\title{
Quality of life among advanced cancer patients in Vietnam: a multicenter cross-sectional study
}

\author{
Bui Thanh Huyen ${ }^{1,2}$. Pham Thi Van $\mathrm{Anh}^{3} \cdot$ Le Dai Duong ${ }^{1,4}$. Than Ha Ngoc The ${ }^{1,4} \cdot$ Ping Guo ${ }^{5}$ Pham Van Thuc ${ }^{6}$. \\ Luong Ngoc Khue ${ }^{7}$ Eric L. Krakauer ${ }^{1,8,9} \cdot$ Richard Harding $^{5}$
}

Received: 6 May 2020 / Accepted: 19 January 2021 / Published online: 3 February 2021

(C) The Author(s) 2021

\begin{abstract}
Purpose Cancer is a leading cause of death in Vietnam. To maximize quality of life (QOL) at the end of life, valid and clinically useful instruments are needed to assess palliative care needs and the effectiveness of palliative care interventions.

Methods We aimed to (i) determine psychometric properties of the Vietnamese version of the WHO abbreviated quality of life scale $\left(W_{H O Q O L-B R E F}\right.$ ) among advanced cancer patients, (ii) measure HR-QOL, and (iii) identify predictors of HR-QOL. We collected demographic, clinical, and HR-QOL data from stage III/IV adult cancer patients at two major Vietnamese cancer centers. We determined the internal consistency (Cronbach's alpha), construct validity (confirmatory factor analysis (CFA)), and discriminant validity (known-groups comparison) of the Vietnamese instrument. HR-QOL was analyzed descriptively. Multinomial logistic regressions identified predictors of HR-QOL.

Results A total of 825 patients participated. Missing data were completely at random (MCAR) $($ chi-square $=14.270, \mathrm{df}=14, p=$ 0.430). Cronbach's alpha for all items was 0.904 . CFA loadings of physical, psychological, social relationship, and environment domains onto HR-QOL were $0.81,0.82,0.34$, and 0.75 , respectively. Prediction of scores differed significantly by functional status (Wilks' lambda $=0.784$, chi-square $=197.546, \mathrm{df}=4, p<0.01$, correct prediction $=74.6 \%$ ). HR-QOL was reported as very bad/bad by $n=188$ patients (22.8\%) and general health as very bad/bad by $n=430(52.1 \%)$. Multinomial logistic regression (likelihood ratio test: chi-square $=35.494, \mathrm{df}=24, p=0.061$, correct prediction $=62.2 \%$ ) and the Pearson correlations revealed worse HR-QOL was associated with inpatient status, high ECOG score, and having dependent children.

Conclusion The Vietnamese version of the WHOQOL-BREF has excellent internal consistency reliability and sound construct and discriminant validity in advanced cancer patients. Advanced cancer inpatients, those with dependent children, and those with poorer physical function appear to have the greatest palliative care needs.
\end{abstract}

Keywords Palliative care $\cdot$ Cancer $\cdot$ Vietnam $\cdot$ Quality of life $\cdot$ Global health

Bui Thanh Huyen, Pham Thi Van Anh, Eric L. Krakauer and Richard Harding contributed equally to this work.

Richard Harding

richard.harding@kcl.ac.uk

1 Department of Palliative Care, University of Medicine and Pharmacy, Ho Chi Minh City, Vietnam

2 City Children's Hospital, Ho Chi Minh City, Vietnam

3 Department of Infectious Diseases, Hai Phong University of Medicine and Pharmacy, Hai Phong, Vietnam

4 Department of Geriatrics and Palliative Care, University Medical Center, Ho Chi Minh City, Vietnam
5 Florence Nightingale Faculty of Nursing, Midwifery and Palliative Care, Cicely Saunders Institute of Palliative Care, Policy and Rehabilitation, King's College London, Bessemer Road, London SE5 9PJ, UK

6 Hai Phong University of Medicine and Pharmacy, Hai Phong, Vietnam

7 Administration of Medical Services, Ministry of Health, Hanoi, Vietnam

8 Department of Global Health and Social Medicine, Harvard Medical School, Boston, USA

9 Division of Palliative Care and Geriatric Medicine, Massachusetts General Hospital, Boston, USA 


\section{Introduction}

Cancer incidence and mortality are rising and as much as $70 \%$ of global cancer incidence may be in LMIC by 2030 [1]. By 2060, an estimated 16 million people with cancer will die annually with serious illness-related suffering, a $109 \%$ increase from 2016 to 2060, with the fastest rise occurring in low-income countries (400\% increase) [2].

A systematic review of symptoms in people with advanced illness revealed that more than half of advanced cancer patients suffer from fatigue, anorexia, pain, worry, and poor selfreported well-being [3]. Health-related quality of life (HRQOL) offers a clinically useful outcome measure beyond morbidity and mortality [4]. Integrated early palliative care improves patient- and family-reported outcomes including quality of life, while reducing costs [5-8]. In response to the huge disparity between high- and middle/lower-income countries in access to palliative care and pain relief [9], the World Health Organization resolved that provision of palliative care is a responsibility of all healthcare systems and affirmed that universal health coverage cannot be achieved without access to palliative care [10].

In 2016, cancer was the leading cause of death in Vietnam, with estimated 164,600 new cancer cases and 114,000 cancerrelated deaths. Cancer is usually diagnosed at a late stage in Vietnam [11] which lacks adequate cancer treatment facilities [12]. No data on HR-QOL of Vietnamese cancer patients currently exist. Therefore, this study aimed to (1) evaluate the psychometric properties of a common measure of HR-QOL as applied to patients with advanced cancer in Vietnam, (2) measure HR-QOL, and (3) identify predictors of HR-QOL.

\section{Methods}

\section{Settings and sample}

This cross-sectional, multicenter self-report study was conducted in two public tertiary referral hospitals in Vietnam: a cancer center in Hanoi (northern region) and a general hospital in Ho Chi Minh City (southern region). The cancer center has 1800 inpatient beds and receives patients from throughout northern Vietnam. The general hospital is in southern Vietnam and has 700 inpatient beds.

We recruited consecutive inpatients and outpatients with stage III or IV cancer according to the 2010 TNM staging criteria, aged at least 18 years old, with the mental capacity to participate in a self-report questionnaire. A minimum sample size of 660 was needed to determine the prevalence of WHOQOL-BREF items with a confidence level of $99 \%$, margin of error $5 \%$, and expected distribution of $50 \%$ using the 2016 estimates of cancer mortality above. Recruitment was stratified by the hospital, with the sample per site proportionate to the number of cancer patients under care within the previous year.

\section{Clinical and demographic variables}

All data were collected by medical and public health students trained in survey interviewing. Demographic information collected included age, gender, ethnicity, region, education, job status, monthly income, household size, marital status, and number of dependent children. Clinical measures included place of care, primary cancer, metastases, stage, year of diagnosis, prior treatment with radiotherapy or chemotherapy, and Eastern Cooperative Oncology Group (ECOG) [13] performance status.

\section{HR-QOL measure}

Data on HR-QOL was collected using the Vietnamese version of the World Health Organization abbreviated quality of life scale (WHOQOL-BREF ${ }_{\mathrm{VN}}$ ) [14]. The WHOQOL-BREF $_{\mathrm{VN}}$ is a validated, multidimensional instrument of 26 items consisting of 4 domains and two global items: HR-QOL and general health. Each global item is rated with a Likert scale from 1 to 5 . The HRQOL score is computed by multiplying the reported HRQOL by 4. Thus, each participant has a HR-QOL score of $4,8,12,16$, or 20 (interpreted as "very bad," "bad," "neither bad nor good," "good," and "very good" HRQOL, respectively). General health is measured in the same way. The remaining 24 items are grouped into four domains: physical (7 items), psychological (6 items), social relationships (3 items), and environment ( 8 items). The value of each domain is calculated by multiplying the average of all items in that domain by 4, giving a continuous numerical variable ranging from 4 to 20 . A higher score represents better patient status.

The original English language WHOQOL-BREF demonstrated good internal consistency reliability (Cronbach's alpha of domains $0.66-0.84$ ). Confirmatory factor analysis (CFA) revealed a stable factor structure, and it has excellent discriminant validity between ill and well participants. The WHOQOL-BREF $_{\mathrm{VN}}$ was found to have excellent internal consistency reliability among people with HIV/AIDS in Vietnam [15] (Cronbach's alpha $=0.61-0.82$ across domains) and people with hypertension in Vietnam (Cronbach's alpha = $0.65-0.88$ across domains) [16].

\section{Data analysis}

IBM SPSS v23 was used for all steps of analysis unless otherwise stated. Little's test of the expectationmaximization (EM) estimated statistics was used to determine the randomness of missing values (MCAR). A 
variable with more than $40 \%$ of data missing was excluded from further analyses. Complete case analysis (listwise deletion method) was applied.

For objective 1, the COSMIN checklist was used to assess properties of the WHOQOL-BREF ${ }_{\mathrm{VN}}$ [17]. For internal consistency, Cronbach's alpha was calculated for total items and each dimension. For structural validity, CFA was conducted using LISREL 8.8 (maximum likelihood estimation (MLE)) to investigate the loadings of the six domains onto the QOL variable. For construct validity, we conducted known-groups comparison, a univariate ANOVA to evaluate the discriminant function between high (ECOG 1) and low (ECOG 2, 3, 4 , or 5) functions.

For objective 2, descriptive statistics were performed, and the percentages of subcategories in overall QOL and general health variables were reported using the midpoint value separating poor and good QOL.

For objective 3, a multinomial logistic regression was performed to identify predictors of HR-QOL score. Step 1 was bivariate analysis of independent variables and dependent variable (HR-QOL) with the Pearson correlation and $p$ value reported. Independent variables associated with the QOL in bivariate analysis at $p \leq 0.2$ in step 1 were retained. Step 2 entailed a correlation matrix to identify pairs of independent variables whose correlation was $\geq 0.8$, with subsequent exclusion of the variable with the larger amount of missing data. Step 3 was multinomial logistic regression with backward entry, excluding independent variables $p>0.05$, rerunning the multinomial logistic regression analysis for the best fit model. Likelihood ratio tests (chi-square, $\mathrm{df}$, and $p$ ) were used to investigate the model fit. A model was considered a good fit to the data if $p \leq 0.05$. The best fit model was the last model having a good fit or the model in which all the $p$ values of independent variables in the model are $<0.05$.

The study was approved by the Institutional Review Boards of Partners Healthcare System in Boston, USA, and the Ministry of Health of Vietnam, and all patients gave written informed consent prior to data collection. The study was performed in accordance with the ethical standards as laid down in the 1964 Declaration of Helsinki and its later amendments.

\section{Results}

\section{Sample characteristics}

We recruited 825 participants, of whom 469 (56.8\%) were recruited from the cancer center in the north and 356 (43.2\%) from the general hospital in the south.

The sample characteristics are presented in Table 1.

\section{Data completeness}

There were 1051 (2.7\%) missing values. Two variables including primary cancer (missing 417, 50.5\%) and metastases (missing 339, 41.1\%) were excluded from analysis. Little's missing completely at random (MCAR) test of expectationmaximization (EM) estimated statistics indicated that missing data were completely at random (chi-square 14.270, df 14, $p$ 0.430).

\section{Objective 1: Evaluate psychometric properties of the WHOQOL-BREF $_{\mathrm{VN}}$}

For internal consistency, Cronbach's alpha for total items of the WHOQOL-BREF ${ }_{\mathrm{VN}}$ was 0.904 . Cronbach's alphas for each domain were 0.85 (physical), 0.734 (psychological), 0.599 (social relationship), and 0.763 (environmental).

With respect to CFA, three (physical, psychological, and environmental) out of four domains are strongly loaded onto the overall QOL item. The loadings were $0.81,0.82,0.75$, and 0.34 for physical, psychological, environmental, and social relationship domains, respectively. The standardized solution of factor loadings is shown in Fig. 1.

With respect to discriminant validity, all domains significantly discriminated between well and ill patients according to ECOG functional status $(p<0.05)$ (Table 2).

Wilks' lambda 0.784, chi-square 197.546, df 4, and $p<0.01$ demonstrate a statistically significant difference in score prediction for the well and ill groups. The four domains correctly predicted values regarding wellness and illness for $76.3 \%$ cases, with accurate predictions being made for $84.7 \%$ of well and $74.6 \%$ for ill patients.

\section{Objective 2: Measure of HR-QOL and general health}

Regarding the four domains of the WHOQOL-BREF ${ }_{\mathrm{VN}}$, median scores of the physical, psychological, social relationships, and environment were 12, 12.67, 13.07, and 12.73, respectively (Table 3). Assuming 12 as the midpoint between bad and good conditions, the participants had neither good nor bad physical, psychological, or environmental conditions and slightly better social relationships.

Concerning HR-QOL, $502(60.8 \%)$ participants perceived neither good nor bad QOL. "Very bad" and "bad" QOL were reported by $n=13(1.6 \%)$ and $n=175(21.2 \%)$, respectively, while $n=127(15.4 \%)$ had "good" and $n=8(1 \%)$ had "very good" QOL. Mean and median of HR-QOL were 11.72 and 12 , respectively (possible range 4 to 20 ). Regarding general health, nearly two-fifths $(n=324,39.3 \%)$ of the subjects had neutral health status. "Very bad" and "bad" general health were reported by $n=44(5.3 \%)$ and $n=386(46.8 \%)$, respectively. "Good" and "very good" general health were reported by $n=68(8.2 \%)$ and $n=3(0.4 \%)$, respectively. The mean and median scores for general health were 10.06 and 8 . 
Table 1 Sample characteristics $(n=825)$

\begin{tabular}{|c|c|c|c|}
\hline Variables & Valid $(n)$ & $\begin{array}{l}\text { Missing data } \\
(n(\%))\end{array}$ & $\begin{array}{l}\text { Sample characteristics } \\
\text { Valid number (percentage) } \\
\text { (total } 100 \% \text { ) }\end{array}$ \\
\hline Study site & 824 & $1(0.1 \%)$ & $\begin{array}{l}\text { Cancer center } 469(56.8 \%) \\
\text { General hospital } 356(43.2 \%)\end{array}$ \\
\hline Gender & 822 & $3(0.4 \%)$ & $\begin{array}{l}\text { Male } 441(53.6 \%) \\
\text { Female } 381(46.4 \%)\end{array}$ \\
\hline Type of patients & 825 & $0(0 \%)$ & $\begin{array}{l}\text { Inpatient } 356(43.2 \%) \\
\text { Outpatient } 501(60.7 \%)\end{array}$ \\
\hline Ethnicity & 823 & $2(0.2 \%)$ & $\begin{array}{l}\text { Kinh } 807(98.1 \%) \\
\text { Others } 16(1.9 \%)\end{array}$ \\
\hline Region & 825 & $0(0 \%)$ & $\begin{array}{l}\text { North } 464(56.2 \%) \\
\text { Center } 9(1.1 \%) \\
\text { South } 352(42.7 \%)\end{array}$ \\
\hline Living location & 825 & $0(0 \%)$ & $\begin{array}{l}\text { Rural } 454(55 \%) \\
\text { Urban } 371(45 \%)\end{array}$ \\
\hline Education & 824 & $1(0.1 \%)$ & $\begin{array}{l}\text { Primary school } 188(22.8 \%) \\
\text { Secondary school } 276(33.5 \%) \\
\text { High school } 238(28.9 \%) \\
\text { College/university } 103(12.5 \%) \\
\text { Postgraduate } 1(0.1 \%) \\
\text { Illiterate } 18(2.2 \%)\end{array}$ \\
\hline Having a paid job & 825 & $0(0 \%)$ & $\begin{array}{l}\text { Yes } 292(35.4 \%) \\
\text { No } 533(64.6 \%)\end{array}$ \\
\hline Average monthly income & 797 & $28(3.4 \%)$ & $\begin{array}{l}\text { Less than } 70 \text { USD: } 362(45.4 \%) \\
70-120 \text { USD: } 155(19.4 \%) \\
\text { 120-165 USD: } 126(15.8 \%) \\
\text { More than 165 USD: } 154(19.3 \%)\end{array}$ \\
\hline Marital status & 823 & $2(0.2 \%)$ & $\begin{array}{l}\text { Single } 44(5.3 \%) \\
\text { Married } 670(81.4 \%) \\
\text { Living together as married } 3(0.4 \%) \\
\text { Separated } 24(2.9 \%) \\
\text { Divorced } 82(10 \%) \\
\text { Widowed } 0(0 \%)\end{array}$ \\
\hline Age & 823 & $2(0.2 \%)$ & Range 20 to 95 , mean 56.28 , SD 12.24 . \\
\hline Household size & 819 & $8(0.8 \%)$ & Range 0 to 12 , median 4 \\
\hline Number of dependent children & 822 & $3(0.3 \%)$ & Range 0 to 9 , median 1 \\
\hline Stable relationship with partner & 813 & $12(1.45 \%)$ & $\begin{array}{l}\text { Yes } 691(85 \%) \\
\text { No } 122(15 \%)\end{array}$ \\
\hline ECOG & 824 & $1(0.1 \%)$ & $\begin{array}{l}\text { ECOG 1: } 138(16.7 \%) \\
\text { ECOG 2: } 352(42.7 \%) \\
\text { ECOG 3: } 206(25 \%) \\
\text { ECOG 4: } 126(15.3 \%) \\
\text { ECOG 5: } 2(0.2 \%)\end{array}$ \\
\hline Place of care & 823 & $2(0.2 \%)$ & $\begin{array}{l}\text { Home } 136(16.5 \%) \\
\text { Inpatient } 378(45.9 \%) \\
\text { Day care } 2(0.2 \%) \\
\text { Outpatient } 307(37.3 \%) \\
\text { Others } 0(0 \%)\end{array}$ \\
\hline Stage of cancer & 729 & $96(11.6 \%)$ & $\begin{array}{l}\text { Stage 3: } 572(78.5 \%) \\
\text { Stage 4: } 157(21.5 \%)\end{array}$ \\
\hline Getting radiotherapy & 806 & $19(2.3 \%)$ & $\begin{array}{l}\text { Yes } 245(30.4 \%) \\
\text { No } 561(69.6 \%)\end{array}$ \\
\hline Getting chemotherapy & 812 & $13(1.6 \%)$ & $\begin{array}{l}\text { Yes } 569(70.1 \%) \\
\text { No } 243(29.9 \%)\end{array}$ \\
\hline Years from diagnosis to interview & 736 & $89(10.78 \%)$ & Range 0 to 24 , median 1 \\
\hline
\end{tabular}


Fig. 1 Factor loadings of four domains onto overall QOL item of the WHOQOL-BREF $\mathrm{VN}$

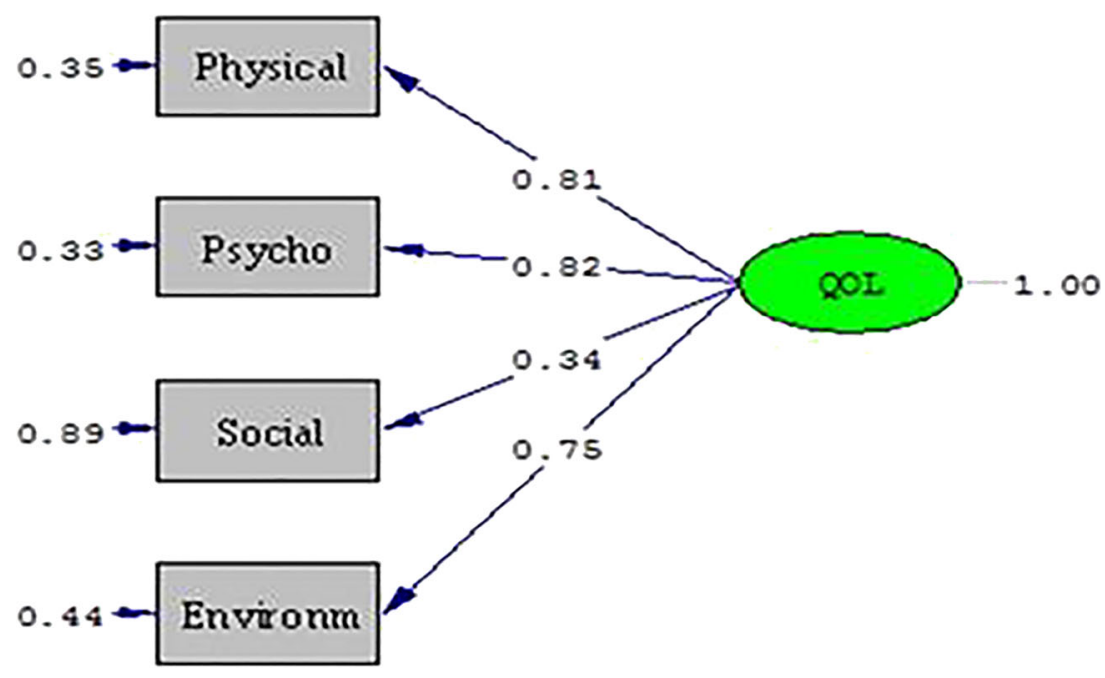

\section{Objective 3: Identify predictors of HR-QOL values}

Step 1 (bivariate analyses) identified 9/20 sample characteristics that yielded $p$ values $>0.2$ (Table 4 ).

The eleven variables were then retained in the correlation matrix which showed that the Pearson correlation between study site and living region was $0.989(p<0.01, N=824)$, so the study site was excluded from further analyses. The multinomial logistic regression generated three models (Table 5), of which model 3 was the best fit.

The best fit model correctly predicted HR-QOL values in $62.2 \%$ of participants. The multinomial logistic regression (likelihood ratio test: chi-square 35.494, df 24, $p$ 0.061, correct prediction $62.2 \%$ ) and Pearson correlations revealed that worse HR-QOL was associated with being an inpatient ( $p=$ $0.015)$, higher ECOG score $(p<0.01)$, and having dependent children $(p<0.01)$.

\section{Discussion}

This is the first study to measure HR-QOL and its predictors among advanced cancer patients in Vietnam and also the first

Table 2 Discriminant validity of domains of the WHOQOL-BREF $\mathrm{VN}_{\mathrm{V}}$ between well and ill groups according to ECOG physical function

Tests of equality of group means

\begin{tabular}{llllll}
\hline & Wilks' lambda & $F$ & df1 & df2 & Sig. \\
\hline Physical & .791 & 215.011 & 1 & 815 & $<0.01$ \\
Psychological & .871 & 120.951 & 1 & 815 & $<0.01$ \\
Social relationship & .994 & 5.212 & 1 & 815 & .023 \\
Environment & .923 & 68.461 & 1 & 815 & $<0.01$ \\
\hline
\end{tabular}

to evaluate the psychometric properties of the WHOQOL$\mathrm{BREF}_{\mathrm{VN}}$ instrument in this population.

We found that the WHOQOL-BREF $\mathrm{VN}_{\mathrm{N}}$ has excellent internal consistency reliability, with Cronbach's alpha of all items of 0.904 and for the physical (0.85), psychological (0.73), and environmental ( 0.763$)$ subscales. It had fair internal consistency reliability in the social relationship subscale (0.599).

In terms of CFA, the WHOQOL-BREF ${ }_{\mathrm{VN}}$ had excellent structural validity with three out of four domains (physical 0.81 , psychological 0.82 , and environmental 0.75 ) strongly loaded onto the HR-QOL item. The social relationship domain played little role in the loading (0.34). The findings are similar to those of the WHOQOL-BREF study, in which the physical domain was the greatest and social relationship the least contributor to the loadings onto the overall QOL item. However, all four domains contributed significantly to explaining observed variance in HR-QOL in prior WHOQOL-BREF studies [18], while social relationships seemed to contribute only slightly in our study. Vietnam has a family-centered cultural tradition. Several generations often live together in the same household, and family members tend to have a strong sense of filial responsibility to care for their parents and relatives [19]. In our study, $81.4 \%$ of the patients were married, and the median of the household size was 4 (range 0-12). We suspect that Vietnamese cancer patients have good family support both when they are relatively well and especially when they are sick and thus do not report a change in this domain.

The WHOQOL-BREF $\mathrm{VN}_{\mathrm{VN}}$ successfully discriminated between groups with better and poorer functional status (Wilks' lambda $=0.784$, chi-square $=197.546, \mathrm{df}=4$, $p<0.01$ ), and all the four domains significantly discriminated between these groups $(p<0.05)$ (Table 5).

HR-QOL in our sample (pro-rated to 50/100) was much lower compared to that in two previous studies: the Vietnamese general population (81.6/100), early-stage HIV- 
Table 3 Descriptive statistics of the four domains of WHOQOLBREF $_{\mathrm{VN}}$

\begin{tabular}{lllll}
\hline & Physical & Psychological & Social relationship & Environment \\
\hline Valid (missing) & $822(3)$ & $820(5)$ & $824(1)$ & $821(4)$ \\
Possible range & $4-20$ & $4-20$ & $4-20$ & $4-20$ \\
Median & 12 & 12.67 & 13.07 & 12.73 \\
Mode & 12 & 13 & 12 & 15 \\
Standard deviation & 2.606 & 2.199 & 1.953 & 2.015 \\
Minimum & 4 & 4 & 7 & 6 \\
Maximum & 20 & 20 & 20 & 20 \\
Percentiles & & & & 11.5 \\
25 & 9.71 & 11.33 & 12 & 13 \\
50 & 12 & 12.67 & 13.33 & 14.5 \\
75 & 13.71 & 14 & 14.67 & \\
\hline
\end{tabular}

infected people (69.3/100), and AIDS patients (65.2/100) [20] and another study of HIV-positive patients on methadone maintenance therapy in Vietnam $(59.7,70,70.8$, and 68.9/ 100 at baseline, 3 months, 6 months, and 9 months, respectively) [15].

Multinomial logistic regression and the Pearson correlation $(r)$ between patient type $(r=0.154, p<0.01)$, number of dependent children $(r=-0.104, p=0.003)$, and ECOG $(r=-$ $0.191, p<0.01)$ indicated that QOL was better among outpatients than inpatients, among patients with few rather than many dependent children, and among patients with a low ECOG score.

Our study had a number of limitations. While we recruited both inpatients and outpatients from both northern and southern regions, convenience sampling and the unknown response rate may have introduced selection bias. In addition, the student interviewers were instructed not to document the primary cancer type or the presence of
Table 4 Bivariate analyses between variables with HR-QOL item $(n=825)$

\begin{tabular}{lllll}
\hline Variables & Valid $(n)$ & Missing data $(n(\%))$ & \multicolumn{2}{l}{$\begin{array}{l}\text { Correlation between variables with } \\
\text { HR-QOL item }\end{array}$} \\
\cline { 4 - 5 } & & & Pearson correlation & $p$ (2-tailed) \\
\hline Study site & 824 & $1(0.1 \%)$ & 0.115 & 0.001 \\
Gender & 822 & $3(0.4 \%)$ & 0.002 & 0.966 \\
Type of patient & 825 & $0(0 \%)$ & 0.154 & $<0.01$ \\
Ethnicity & 823 & $2(0.2 \%)$ & 0.041 & 0.246 \\
Region & 825 & $0(0 \%)$ & 0.111 & 0.001 \\
Living location & 825 & $0(0 \%)$ & 0.179 & $<0.01$ \\
Education & 824 & $1(0.1 \%)$ & 0.071 & 0.041 \\
Having a paid job & 825 & $0(0 \%)$ & -0.05 & 0.148 \\
Average monthly income & 797 & $28(3.4 \%)$ & 0.162 & $<0.01$ \\
Marital status & 823 & $2(0.2 \%)$ & 0.014 & 0.686 \\
Age & 823 & $2(0.2 \%)$ & 0.104 & 0.003 \\
Household size & 819 & $8(0.8 \%)$ & 0.012 & 0.733 \\
Number of dependent children & 822 & $3(0.3 \%)$ & -0.104 & 0.003 \\
Stable relationship with partner & 813 & $12(1.45 \%)$ & 0.019 & 0.587 \\
ECOG & 824 & $1(0.1 \%)$ & -0.191 & $<0.01$ \\
Place of care & 823 & $2(0.2 \%)$ & -0.034 & 0.324 \\
Stage of cancer & 729 & $96(11.6 \%)$ & -0.038 & 0.306 \\
Getting radiotherapy & 806 & $19(2.3 \%)$ & 0.014 & 0.691 \\
Getting chemotherapy & 812 & $13(1.6 \%)$ & 0.057 & 0.103 \\
Years from diagnosis to interview & 736 & $89(10.78 \%)$ & 0.01 & 0.796 \\
\hline & & & &
\end{tabular}


Table 5 Likelihood ratio test of the multinomial logistic regression and the percentage of participants for which the models correctly predicted HRQOL values

\begin{tabular}{|c|c|c|c|c|c|c|}
\hline \multirow[t]{2}{*}{ Model } & \multirow[t]{2}{*}{ Variables } & \multirow[t]{2}{*}{ Valid (excluded cases) } & \multicolumn{3}{|c|}{ Likelihood ratio tests } & \multirow{2}{*}{$\begin{array}{l}\text { Percent correct } \\
\text { of prediction }\end{array}$} \\
\hline & & & $\begin{array}{l}\text { Chi- } \\
\text { square }\end{array}$ & Df & $P$ & \\
\hline Model 1 & $\begin{array}{l}10 \text { independent variables (type of patient, age, region, } \\
\text { living location, education, paid job, monthly income, } \\
\text { dependent children, ECOG, chemotherapy) }\end{array}$ & $779(46)$ & 74.493 & 76 & 0.53 & 61.5 \\
\hline Model 2 & $\begin{array}{l}6 \text { independent variables (dependent children, } \\
\text { type of patient, region, education, paid job, ECOG) }\end{array}$ & $820(5)$ & 66.958 & 56 & 0.15 & 60.7 \\
\hline Model 3 & Dependent children, type of patient, ECOG & $821(4)$ & 35.494 & 24 & 0.061 & 62.2 \\
\hline
\end{tabular}

metastatic disease unless these were certain, and uncertainty was frequent either because the precise diagnosis was not clear or because the interviewer could not determine the diagnosis with certainty. Thus, we were not able to determine the association of cancer type of metastatic disease with the outcomes. However, the results from the MCAR analysis suggest that the missing data did not affect our findings [21]. We also note that this crosssectional study did not assess test-retest reliability or responsiveness. Also, while the WHOQOL-BREF enables comparison with other clinical populations, face and content validities are not established for advanced disease.

This is the first study to measure HR-QOL of Vietnamese advanced cancer patients. We have demonstrated excellent internal consistency reliability and sound construct and discriminant validity of the WHOQOL-BREF $\mathrm{VN}_{\mathrm{N}}$ in this population.

The majority of participants $(77.2 \%)$ had acceptable HRQOL, but a notable minority $(22.8 \%)$ perceived bad or very bad HR-QOL. All advanced cancer patients should have access to palliative care assessment and interventions. Qualitative studies are needed to articulate the palliative care needs of patients with poor HR-QOL.

Lastly, multinomial logistic regressions revealed that poor ECOG, being an inpatient, and having dependent children were predictors of poor HR-QOL values. Therefore, more attention should be paid to patients having poor ECOG performance status, and social-psychological support should be accessible for inpatients or patients with dependent children.

As cancer-associated suffering and mortality increase in low- and middle-income countries, patient-reported quality of life should be prioritized as an outcome measure for health systems to ensure relief from unnecessary suffering. The WHO has resolved that palliative care is an ethical responsibility of health systems and that universal access to it is necessary to achieve universal health coverage [22]. Reliable measurement of patient-reported quality of life is necessary to assure that palliative care is effective.
Authors contribution Conceived and designed the study: BTH, PVA, ELK, RH. Performed the study: BTH, PVA, LDD, THNT. Analyzed the data: BTH, PVA, ELK, PG, RH, LDD. Contributed reagents/materials/analysis tools: PG, PVT, LNK, ELK, THNT, RH. Wrote the paper: BTH, PVA, LDD, ELK, RH

Funding This study was supported by an unrestricted grant from the Open Society Foundations.

Code availability Not applicable.

Availability of data and material Data are available from the authors upon reasonable request.

Standards of reporting Strobe statement completed.

\section{Declarations}

Ethics approval The study was approved by the Institutional Review Boards of Partners Healthcare System in Boston, USA, and the Ministry of Health of Vietnam.

Consent to participate All patients gave written informed consent prior to data collection.

Consent for publication All patients gave written informed consent prior to data collection.

Conflict of interest The authors declare no competing interests.

Open Access This article is licensed under a Creative Commons Attribution 4.0 International License, which permits use, sharing, adaptation, distribution and reproduction in any medium or format, as long as you give appropriate credit to the original author(s) and the source, provide a link to the Creative Commons licence, and indicate if changes were made. The images or other third party material in this article are included in the article's Creative Commons licence, unless indicated otherwise in a credit line to the material. If material is not included in the article's Creative Commons licence and your intended use is not permitted by statutory regulation or exceeds the permitted use, you will need to obtain permission directly from the copyright holder. To view a copy of this licence, visit http://creativecommons.org/licenses/by/4.0/. 


\section{References}

1. International Agency for Research on Cancer. (2008). World Cancer Report 2008. In L. Bernard, \& B. Peter (Eds.). WHO, Geneva.

2. Sleeman KE, de Brito M, Etkind S, Nkhoma K, Guo P, Higginson IJ, Gomes B, Harding R (2019) The escalating global burden of serious health-related suffering: projections to 2060 by world regions, age groups, and health conditions. Lancet Glob Health 7(7): e883-e892. https://doi.org/10.1016/S2214-109X(19)30172-X

3. Moens K, Higginson IJ, Harding R, IMPACT, E (2014) Are there differences in the prevalence of palliative care-related problems in people living with advanced cancer and eight non-cancer conditions? A systematic review. J Pain Symptom Manag 48(4):18677. https://doi.org/10.1016/j.jpainsymman.2013.11.009

4. Etkind SN, Daveson BA, Kwok W, Witt J, Bausewein C, Higginson IJ, Murtagh FEM (2015) Capture, transfer, and feedback of patient-centered outcomes data in palliative care populations: does it make a difference? A systematic review. [research support, non-U S Gov't review]. J Pain Symptom Manag 49(3):611-624

5. Temel JS, Greer JA, Muzikansky A, Gallagher ER, Admane S, Jackson VA, Dahlin CM, Blinderman CD, Jacobsen J, Pirl WF, Billings JA, Lynch TJ (2010) Early palliative care for patients with metastatic non-small-cell lung cancer. N Engl J Med 363(8):733742. https://doi.org/10.1056/NEJMoa1000678

6. Zimmermann C, Swami N, Krzyzanowska M, Hannon B, Leighl N, Oza A, Moore M, Rydall A, Rodin G, Tannock I, Donner A, Lo C (2014) Early palliative care for patients with advanced cancer: a cluster-randomised controlled trial. Lancet 383(9930):1721-1730. https://doi.org/10.1016/S0140-6736(13)62416-2

7. Higginson IJ, Bausewein C, Reilly CC, Gao W, Gysels M, Dzingina M, McCrone P, Booth S, Jolley CJ, Moxham J (2014) An integrated palliative and respiratory care service for patients with advanced disease and refractory breathlessness: a randomised controlled trial. Lancet Respir Med 2(12):979-987. https://doi.org/ 10.1016/S2213-2600(14)70226-7

8. Temel JS, Greer JA, El-Jawahri A, Pirl WF, Park ER, Jackson VA et al (2017) Effects of early integrated palliative care in patients with lung and GI cancer: a randomized clinical trial. J Clin Oncol 35(8):834-841. https://doi.org/10.1200/JCO.2016.70.5046

9. Knaul FM, Farmer PE, Krakauer EL, De Lima L, Bhadelia A, Jiang Kwete $\mathrm{X}$ et al (2017) Alleviating the access abyss in palliative care and pain relief-an imperative of universal health coverage: the Lancet Commission report. Lancet 391:1391-1454. https://doi. org/10.1016/S0140-6736(17)32513-8

10. Strengthening of palliative care as a component of comprehensive care throughout the life course WHA67.19 (2014). http://apps.who. int/gb/ebwha/pdf files/WHA67/A67 R19-en.pdf. Accessed 10/05/ 162016
11. Observatory, G. C. http://gco.iarc.fr/today/data/factsheets/ populations/704-viet-nam-fact-sheets.pdf. Accessed 03/02/2021

12. Anh PT, Duc NB (2002) The situation with cancer control in Vietnam. Jpn J Clin Oncol 32(Suppl):S92-S97. https://doi.org/10. 1093/jjco/hye127

13. Oken MM, Creech RH, Tormey DC, Horton J, Davis TE, McFadden ET, Carbone PP (1982) Toxicity and response criteria of the Eastern Cooperative Oncology Group. Am J Clin Oncol 5(6):649-655

14. The WHOQOL Group (1998) Development of the World Health Organization WHOQOL-BREF quality of life assessment. Psychol Med 28(3):551-558. https://doi.org/10.1017/s0033291798006667

15. Tran BX, Ohinmaa A, Duong AT, Do NT, Nguyen LT, Nguyen QC, Mills S, Jacobs P, Houston S (2012) Changes in drug use are associated with health-related quality of life improvements among methadone maintenance patients with HIV/AIDS. Qual Life Res 21(4):613-623. https://doi.org/10.1007/s11136-011-9963-y

16. Ha NT, Duy HT, Le NH, Khanal V, Moorin R (2014) Quality of life among people living with hypertension in a rural Vietnam community. BMC Public Health 14:833. https://doi.org/10.1186/14712458-14-833

17. Mokkink LB, Terwee CB, Knol DL, Stratford PW, Alonso J, Patrick DL, Bouter LM, de Vet HCW (2010) The COSMIN checklist for evaluating the methodological quality of studies on measurement properties: a clarification of its content. BMC Med Res Methodol 10:22. https://doi.org/10.1186/1471-2288-10-22

18. Skevington SM, Lotfy M, O'Connell KA, Group, W (2004) The World Health Organization's WHOQOL-BREF quality of life assessment: psychometric properties and results of the international field trial. A report from the WHOQOL group. Qual Life Res 13(2): 299-310. https://doi.org/10.1023/B:QURE.0000018486.91360.00

19. Miyawaki CE (2015) A review of ethnicity, culture, and acculturation among Asian caregivers of older adults (2000-2012). SAGE Open 5(1):215824401456636. https://doi.org/10.1177/ 2158244014566365

20. Tran BX, Ohinmaa A, Nguyen LT, Nguyen TA, Nguyen TH (2011) Determinants of health-related quality of life in adults living with HIV in Vietnam. AIDS Care 23(10):1236-1245. https://doi. org/10.1080/09540121.2011.555749

21. Bennett DA (2001) How can I deal with missing data in my study? Aust N Z J Public Health 25(5):464-469

22. World Health Organisation. Universal Health Coverage. http:// www.who.int/mediacentre/factsheets/fs395/en/. Accessed 08/02/ 2018

Publisher's note Springer Nature remains neutral with regard to jurisdictional claims in published maps and institutional affiliations. 